\title{
Comparative efficacy of orally and topically administered $\beta$ blockers for chronic simple glaucoma
}

\author{
JOHN WILliAMSON, J D H YOUNG, H ATTA, GORDON MUIR, AND H KADOM
}

From the Department of Ophthalmology, Southern General Hospital, Govan Road, Glasgow G51 4TF

SUMMARY This open study of $\beta$ blockers in chronic simple glaucoma compared the efficacy of once daily (o.d.) oral nadolol therapy with twice daily (b.d.) topical timolol therapy. Sixty eight patients were randomly assigned to starting doses of either 20,40 , or $80 \mathrm{mg}$ of nadolol o.d. (51 patients) or $0.25 \%$ timolol b.d. (17 patients) and were seen at weekly intervals for a four-week (short-term) period. Upward dosage titration $(80 \mathrm{mg}$ o.d. maximum, nadolol and $0.5 \%$ b.d. maximum, timolol) was permitted if, at any visit, the intraocular pressure (IOP) in either eye was greater than 21 $\mathrm{mmHg}$. At the end of 4 weeks the IOPs of a comparable number of patients were controlled (IOP $<22 \mathrm{mmHg}$ ) with $20 \mathrm{mg}$ nadolol o.d. and $0.25 \%$ timolol b.d. The $40 \mathrm{mg}$ and $80 \mathrm{mg}$ o.d. nadolol regimens were comparable with each other, superior to the $20 \mathrm{mg}$ regimen, and (at least) equivalent to $0.5 \%$ timolol. The absolute degree of IOP reduction achieved with oral nadolol was equivalent to that with topical timolol. Alterations in blood pressure and heart rate were predictably greater with the orally administered $\beta$ blocker. Long-term therapy (up to 24 months) in 28 nadolol patients and 5 timolol patients indicates no more likelihood of tolerance with nadolol therapy. Patient withdrawals from the study due to adverse reactions occurred with nadolol but not timolol. Since oral nadolol administered once daily is as efficacious as b.d. topical timolol, it can be recommended as first-line therapy for certain subsets of the glaucoma clinic population.

\begin{abstract}
The results of a double-blind study of the ocular hypotensive effect of low oral doses of nadolol $(10$, 20,40 , and $80 \mathrm{mg}$, once daily) in normal volunteers are reported.' Considerable dose related reductions $(30 \%$ to $40 \%)$ of intraocular pressure (IOP) were obtained and were maintained for 24 hours with the $40 \mathrm{mg}$ and $80 \mathrm{mg}$ doses. There was a slight loss of effect after this time interval with the two lower doses, but reductions $20 \%$ or more were preserved. Previously published reports of the ocular hypotensive effect in normal subjects of oral propranolol and atenolol at corresponding or higher doses $(40 \mathrm{mg}$ b.d. and $50 \mathrm{mg}$ b.d., respectively) showed IOP reductions of up to $25 \% .^{23}$ Thus, in view of what was considered to be an excellent IOP lowering potential of even low doses of nadolol, we have compared the efficacy of three regimens of once daily oral nadolol $(20,40$, and $80 \mathrm{mg}$ ) with the two standard twice daily regimens of topical timolol $(0.25 \%$ and $0.5 \%)$ in patients with chronic simple glaucoma.
\end{abstract}

Correspondence to Dr J Williamson.
A further consideration in undertaking this study has been the growing awareness in recent years that an increasing number of patients in our glaucoma clinic population are receiving oral $\beta$ blockers for a variety of conditions. If $\beta$ blockers, so administered, can reduce IOP to acceptable levels during chronic administration, then there is clearly a justification for rationalisation of therapy in these patients in the interests of good practice and safety, if not economy.

\section{Material and methods}

\section{SUBJECTS}

This was an open study conducted at two centres to compare the efficacy of three regimens of once daily, orally administered, nadolol $(20,40$, and $80 \mathrm{mg})$ with that of twice daily, topically administered, timolol $(0.25 \%$ and $0.5 \%)$ in the treatment of chronic simple glaucoma. Sixty eight patients (32 men and 36 women), mean age 59 years (range 29-81), were randomised to begin treatment with one of the three nadolol dosages $0 . d$. $(n=51)$ or with a starting dose of 
$0 \cdot 25 \%$ timolol b.d. $(n=17)$. Patients were considered to have chronic simple glaucoma if their IOPs when not taking medication were greater than $21 \mathrm{mmHg}$ by Goldmann applanation tonometry, and if there was coexisting characteristic abnormality in their visual fields or optic nerve heads or both. Exclusion criteria were as described for the normal volunteers' study,' and in addition patients were ineligible if there was electrocardiographic (ECG) evidence of defective cardiac conduction or left ventricular hypertrophy. Written informed consent was obtained from all subjects, and the study protocol was approved by the ethics committee in each centre.

\section{PROCEDURE}

After a general physical examination and ECG screening eligible patients entered a one- to fourweek washout period, during which no glaucoma medication was prescribed. When the IOP in both eyes rose above $21 \mathrm{mmHg}$ patients were randomised to one of four initial treatment groups: once daily nadolol 20,40 , or $80 \mathrm{mg}$; or $0 \cdot 25 \%$ timolol, one drop to each eye b.d. The study design was as follows:

$$
\begin{array}{lrl}
1-4 \text { Wecks } & \rightarrow & 4 \text { Wecks } \\
\text { washout } & \text { short-term } & \rightarrow \text { Up to } 2 \text { ycars } \\
\text { long-term }
\end{array}
$$

Short-term. At the beginning of the short-term portion of the study the following baseline measurements were recorded: Goldmann applanation tonometry; pulse and blood pressure readings (after $5 \mathrm{~min}$ supine); visual acuity; accommodation; pupillometry; refraction; and Schirmer tear test. In addition the visual fields of both eyes of patients in the nadolol treatment groups were charted. At each weekly short-term visit patients returned approximately three to six hours after their morning medication for measurement of IOP, heart rate, and blood pressure. At the final short-term visit (4 weeks) measurements of the additional ocular parameters (except fields) were again taken. At any visit during short-term, if the IOP in either eye was greater than $21 \mathrm{mmHg}$, patients in the nadolol $20 \mathrm{mg}$ or $40 \mathrm{mg}$ treatment groups could have their dosage doubled, and patients receiving $0.25 \%$ timolol b.d. could switch to $0.5 \%$ b.d. However, the maximum dose of nadolol allowed was $80 \mathrm{mg}$ once daily and of timolol $0.5 \%$ b.d. An additional visit during the final week of short-term therapy permitted IOP measurements to be made 23-24 hours after the previous morning's dose of nadolol and 11-12 hours after the previous evening's dose of timolol.

Long-term. Patients treated successfully with nadolol during short-term (IOP $<22 \mathrm{mmHg}$, both eyes) were asked to continue the drug for long-term monitoring. During this long-term period IOPs, blood pressures, and heart rates were measured at monthly intervals with the same upward dosage titration provision as before. The additional ocular measurements (including fields) taken at the baseline visit was repeated at four-monthly intervals. The study protocol did not call for the long-term followup of timolol treated patients but, in the event, one of us (JW) did follow up a limited number of patients.

Statistical comparisons. Baseline characteristics of patients were compared by one way analysis of variance and Duncan's multiple range test. Changes in IOP were compared (where applicable) by one way analysis of covariance, which adjusts for pretreatment differences.

\section{Results}

IOP CONTROL-SHORT-TERM

All 68 patients randomised to treatment groups provided data suitable for evaluation. There were no statistically significant differences among the four initial treatment groups in terms of baseline IOPs, duration of prior glaucoma therapy, or numbers of patients previously requiring multiple drug therapy. The mean age of patients randomised to $20 \mathrm{mg}$ nadolol was, however, less than that of patients initially assigned to the $40 \mathrm{mg}$ dose $(\mathrm{p}<0 \cdot 05)$.

The clinical course of patients during four weeks of short-term therapy is shown in Fig. 1. Forty $(78 \%)$ of the nadolol treated patients were controlled (IOP
Fig. 1 The clinical course of patients during four weeks of short term therapy.

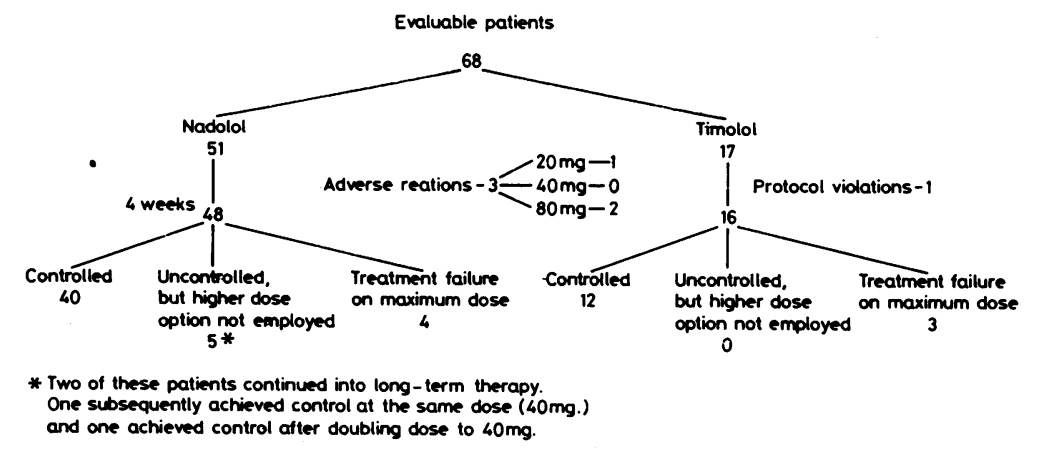


Table 1 Distribution of patients by treatment group and dose at each visit

\begin{tabular}{|c|c|c|c|c|c|}
\hline \multirow[t]{2}{*}{$\begin{array}{l}\text { Initial dose } \\
\text { group }\end{array}$} & $\begin{array}{l}\text { Week } \\
l\end{array}$ & $\begin{array}{l}\text { Week } \\
2\end{array}$ & $\begin{array}{l}\text { Week } \\
3\end{array}$ & $\begin{array}{l}\text { Week } \\
4\end{array}$ & $\begin{array}{l}\text { Last } \\
\text { short } \\
\text { term }^{*}\end{array}$ \\
\hline & \multicolumn{5}{|c|}{ No of patients } \\
\hline \multicolumn{6}{|c|}{ Nadolol $20 \mathrm{mg}(\mathrm{n}=17)$} \\
\hline $20 \mathrm{mg}$ & 17 & 14 & 10 & 10 & 10 \\
\hline $40 \mathrm{mg}$ & 0 & 3 & 6 & 5 & 6 \\
\hline $80 \mathrm{mg}$ & 0 & 0 & 0 & 1 & 1 \\
\hline \multicolumn{6}{|c|}{ Nadolol $40 \mathrm{mg}(\mathrm{n}=18)$} \\
\hline $40 \mathrm{mg}$ & 18 & 18 & 17 & 17 & 17 \\
\hline $80 \mathrm{mg}$ & 0 & 0 & 1 & 1 & 1 \\
\hline \multicolumn{6}{|c|}{ Nadolol $80 \mathrm{mg}(\mathrm{n}=16)$} \\
\hline $80 \mathrm{mg}$ & 16 & 16 & 14 & $13 \dagger$ & $15 \dagger$ \\
\hline \multicolumn{6}{|c|}{ Timolol $0 \cdot 25 \%(n=17)$} \\
\hline $0 \cdot 25 \%$ & 17 & 9 & 9 & 9 & 10 \\
\hline $0 \cdot 5 \%$ & 0 & 7 & 6 & 4 & 7 \\
\hline
\end{tabular}

*One, two, and four patients dropped out of the nadolol $20 \mathrm{mg}, 80$ $\mathrm{mg}$; and timolol $0 \cdot 25 \%$ groups prior to week four.

†Dosage was reduced to $40 \mathrm{mg}$ in one patient.

Table 2 Effect of nadolol on IOP: short-term therapy (four weeks)

\begin{tabular}{|c|c|c|c|c|c|}
\hline \multirow{2}{*}{$\begin{array}{l}\text { Initial } \\
\text { dose } \\
\text { group }\end{array}$} & \multirow[t]{2}{*}{$n$} & & \multicolumn{3}{|c|}{ Final daily dosage } \\
\hline & & & $\begin{array}{l}\text { Nadolol } \\
20 \mathrm{mg}\end{array}$ & $\begin{array}{l}\text { Nadolol } \\
40 \mathrm{mg}\end{array}$ & $\begin{array}{l}\text { Nadolol } \\
80 \mathrm{mg}\end{array}$ \\
\hline Nadolol $20 \mathrm{mg}$ & 17 & $\begin{array}{l}\text { Controlled* } \\
\text { Uncontrolled } \\
\text { D/C, ADR }\end{array}$ & $\begin{array}{l}7 \\
3 \\
0\end{array}$ & $\begin{array}{l}4 \\
1 \\
1\end{array}$ & $\begin{array}{l}1 \\
0 \\
0\end{array}$ \\
\hline Nadolol $40 \mathrm{mg}$ & 18 & $\begin{array}{l}\text { Controlled* } \\
\text { Uncontrolled } \\
\text { D/C, ADR }\end{array}$ & $\begin{array}{l}0 \\
0 \\
0\end{array}$ & $\begin{array}{r}16 \\
1 \\
0\end{array}$ & $\begin{array}{l}1 \\
0 \\
0\end{array}$ \\
\hline Nadolol $80 \mathrm{mg}$ & 16 & $\begin{array}{l}\text { Controlled* } \\
\text { Uncontrolled } \\
\text { D/C, ADR }\end{array}$ & $\begin{array}{l}0 \\
0 \\
0\end{array}$ & $\begin{array}{l}1 \\
0 \\
2\end{array}$ & $\begin{array}{r}10 \\
3 \\
0\end{array}$ \\
\hline
\end{tabular}

$\mathrm{D} / \mathrm{C}=$ Discontinued

$\mathrm{ADR}=$ Adverse reaction

*IOP less than $22 \mathrm{mmHg}$ (both cyes).

Table 3 Short-term outcome by initial and final timolol dosage

\begin{tabular}{|c|c|c|c|c|}
\hline \multirow{2}{*}{$\begin{array}{l}\text { Initial } \\
\text { dose } \\
\text { group }\end{array}$} & \multirow[t]{2}{*}{$n$} & & \multicolumn{2}{|l|}{$\begin{array}{l}\text { Final dosage } \\
\text { (b.d.) }\end{array}$} \\
\hline & & & Timolol $0 \cdot 25 \%$ & Timolol $0.5 \%$ \\
\hline Timolol $0 \cdot 25 \%$ & 17 & $\begin{array}{l}\text { Controlled* } \\
\text { Uncontrolled } \\
\text { D/C.ADR }\end{array}$ & $\begin{array}{l}9 \\
1 \\
0\end{array}$ & $\begin{array}{l}3 \\
4 \\
0\end{array}$ \\
\hline
\end{tabular}

$\mathrm{D} / \mathrm{C}=$ Discontinued

$\mathrm{ADR}=$ Adverse reaction.

*IOP less than $22 \mathrm{mmHg}$ (both eycs).
$<22 \mathrm{mmHg}$ in each eye) by the end of the four week period as were $12(71 \%)$ of the timolol treated patients. Five of the nadolol patients who were uncontrolled at this time still had the option of a higher dose regimen. One of these patients proceeded into long-term therapy at a higher dose $(40 \mathrm{mg})$ and achieved control. Another proceeded into long-term at the same dose $(40 \mathrm{mg})$ and also achieved control. There was no statistically significant difference between nadolol treatment and timolol in terms of IOP control at the end of the short-term period.

The distribution of patients by treatment group and dose throughout the short-term period is shown in Table 1. Of the 17 patients on $20 \mathrm{mg}$ of nadolol six progressed to a $40 \mathrm{mg}$ and one to an $80 \mathrm{mg}$ dose. Among 18 patients randomised to $40 \mathrm{mg}$ nadolol one progressed to an $80 \mathrm{mg}$ dose, and among 16 patients starting with an $80 \mathrm{mg}$ dose one was reduced to $40 \mathrm{mg}$ (downward titration was not part of the protocol). Seven of the 17 patients receiving timolol progressed to the more concentrated dosage form. Tables 2 and 3 illustrate the therapeutic outcome of short-term therapy (that is, control or lack of IOP control) according to initial and final dosage. A similar efficacy pattern was observed for the nadolol $20 \mathrm{mg}$ and timolol $0.25 \%$ regimens, and for the nadolol 40 $\mathrm{mg}$ and $80 \mathrm{mg}$ regimens. However, a majority of the seven patients titrated to the higher concentration of timolol did not show control of IOP.

Mean IOP reductions produced by the dose levels actually employed during weeks 1 and 4 are shown in Table 4. Only those measurements at the end of week 1 provide a comparison of the randomly assigned starting doses, as they were obtained prior to any dose titration. At that time the mean $18.4 \%$ IOP reduction achieved with the $20 \mathrm{mg}$ nadolol regimen was less $(p<0.05)$ than that achieved with the nadolol $40 \mathrm{mg}$ and $80 \mathrm{mg}$ regimens $(31.4 \%$ and $31 \%$ reductions, respectively) but not significantly different from the $0.25 \%$ timolol regimen (24.4\% reduction).

If nadolol and timolol treatments are considered regardless of dosage, by the end of week four the mean IOP had decreased by $30.7 \%$ with nadolol from $27.9 \mathrm{mmHg}$ to $19.1 \mathrm{mmHg}$, and by $34.6 \%$ with timolol from $26.6 \mathrm{mmHg}$ to $17.8 \mathrm{mmHg}$.

\section{DURATION OF IOP EFFECT}

IOP measurements taken immediately prior to the next dose were obtained for all patients towards the end of week 4. Mean pressure reductions 23 to 24 hours after the last nadolol dose and 11 to 12 hours after the last timolol dose are shown in Table 5. Statistical analyses were not made because the original randomisation scheme no longer applied but pressure reductions remained substantial at all dose levels. The IOPs of some patients on the $20 \mathrm{mg}$ and 
Table 4 Mean intraocular pressure (IOP) reductions

\begin{tabular}{|c|c|c|c|c|c|}
\hline & \multicolumn{5}{|l|}{ Actual dose } \\
\hline & $\begin{array}{l}\text { Nadolol } 20 \mathrm{mg} \\
\text { o.d. }\end{array}$ & $\begin{array}{l}\text { Nadolol } 40 \mathrm{mg} \\
\text { o.d. }\end{array}$ & $\begin{array}{l}\text { Nadolol } 80 \mathrm{mg} \\
\text { o.d. }\end{array}$ & $\begin{array}{l}\text { Timolol } 0 \cdot 25 \% \\
\text { b.d. }\end{array}$ & $\begin{array}{l}\text { Timolol } \\
0 \cdot 5 \% \text { b.d. }\end{array}$ \\
\hline \multicolumn{6}{|l|}{ Weck 1} \\
\hline $\mathbf{n}$ & 17 & 18 & 16 & 17 & () \\
\hline Mean pretreatment IOP & $28 \cdot 6$ & $28 \cdot 1$ & $27 \cdot()$ & $26 \cdot 7$ & () \\
\hline Mean post-treatment IOP & $22 \cdot 6$ & $19 \cdot 1$ & $18 \cdot 7$ & $20 \cdot 3$ & () \\
\hline Mcan changet & $-18 \cdot 4 \% *$ & $-31 \cdot 4 \%$ & $-31 \cdot() \%$ & $-24 \cdot 4 \%$ & () \\
\hline \multicolumn{6}{|l|}{ Weck 4† } \\
\hline n & 10 & 23 & 15 & 9 & 4 \\
\hline Mean pretreatment IOP & $25 \cdot 9$ & $28 \cdot 4$ & $28 \cdot 4$ & $26 \cdot()$ & $28 \cdot 0$ \\
\hline Mean post-treatment IOP & $19 \cdot 5$ & $18 \cdot 8$ & $19 \cdot 2$ & $16 \cdot 1$ & $22 \cdot()$ \\
\hline Mean change $\ddagger$ & $-24 \cdot 8 \%$ & $-33 \cdot 8 \%$ & $-32 \cdot 4 \%$ & $-38 \cdot(0 \%$ & $-21 \cdot 5 \%$ \\
\hline
\end{tabular}

*Differs from mcan reductions observed with nadolol $40 \mathrm{mg}$ and nadolol $80 \mathrm{mg}, \mathrm{p}<() \cdot 05$.

†Statistical analysis inappropriatc-original randomisation no longer obtains.

$\ddagger$ Adjusted for pretreatment differences.

Table 5 Mean intraocular pressure reductions: 23-24 hours after last nadolol and 11-12 hours after last timolol dose*

\begin{tabular}{|c|c|c|c|c|c|}
\hline & \multicolumn{5}{|l|}{ Actual dose } \\
\hline & $\begin{array}{l}\text { Nadolol } 20 \mathrm{mg} \\
\text { o.d. }\end{array}$ & $\begin{array}{l}\text { Nadolol } 40 \mathrm{mg} \\
\text { o.d. }\end{array}$ & $\begin{array}{l}\text { Nadolol } 80 \mathrm{mg} \\
\text { o.d. }\end{array}$ & $\begin{array}{l}\text { Timolol } 0 \cdot 25 \% \\
\text { b.d. }\end{array}$ & $\begin{array}{l}\text { Timolol } \\
0 \cdot 5 \% \text { b.d. }\end{array}$ \\
\hline $\mathbf{n}$ & 10 & 23 & 15 & 9 & 4 \\
\hline Mean pretreatment IOP & $25 \cdot 9$ & $28 \cdot 4$ & $28 \cdot 4$ & $26 \cdot 0$ & $28 \cdot 0$ \\
\hline Mean post-treatment IOP & $21 \cdot 6$ & $21 \cdot 3$ & $21 \cdot 8$ & $18 \cdot 0$ & $22 \cdot 1$ \\
\hline Mean changet & $-16 \cdot 6 \%$ & $-25 \cdot 0 \%$ & $-23 \cdot 4 \%$ & $-30 \cdot 8 \%$ & $-21 \cdot 1 \%$ \\
\hline
\end{tabular}

*Statistical analysis inappropriate-original randomisation no longer obtains.

$\uparrow$ Adjusted for pretreatment differences.

$40 \mathrm{mg}$ nadolol regimens in one of our centres (J.D.H.Y.). 'escaped' from control at the 24-hour time point. However, in these patients it was found that the same total daily dose given b.d. was satisfactory.

\section{BLOOD PRESSURE AND HEART RATE}

Reductions in blood pressure and heart rate in patients receiving nadolol closely corresponded to those observed in the normal volunteer study.' Systolic pressure, diastolic pressure, and heart rate decreases ranged from 5 to $9 \%, 8$ to $10 \%$ and 16 to $19 \%$.

\section{IOP CONTROL-LONG-TERM}

The clinical course of the 38 patients ( 33 nadolol and 5 timolol) studied for up to two years is shown in Fig. 2 . At the last visit during this period (mean 12.3 months) $25(76 \%)$ of the 33 patients on nadolol were controlled; two were discontinued as treatment failures on $40 \mathrm{mg}$ daily without employing the option of a higher dose; and one was a treatment failure at the maximum dose. Of the five patients entering long-term therapy on timolol two were controlled at the final visit (mean 11.2 months), and the others were discontinued as treatment failures at the maximum $0.5 \%$ concentration. Table 6 illustrates the outcome (that is, control or lack of control) for patients on long-term nadolol therapy according to initial and final dosages. All but two of 23 nadolol patients entering long-term therapy on the $20 \mathrm{mg}$ and $40 \mathrm{mg}$ dosages were controlled by one or the other of these regimens, excluding four who were controlled but were discontinued because of adverse drug reactions.

All five patients in one centre (J.W.) who were receiving $80 \mathrm{mg}$ of nadolol at month 12 were reduced to a $40 \mathrm{mg}$ dose and remained controlled at month 24 .

\section{SAFETY}

Nadolol administered orally had no effect on visual acuity, accommodation, refraction, pupil size, or tear production. During the relatively brief period of this study there was no evidence of visual field deterioration in any patient.

The numbers of patients discontinued as a result of adverse reactions and the treatment regimens employed at the time of discontinuation can be seen 


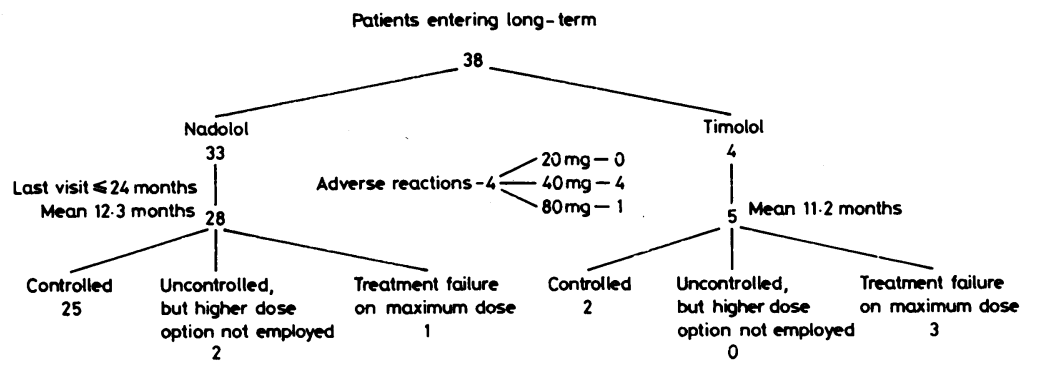

Fig. 2 The clinical course of patients during long term therapy, up to 24 months.

Table 6 Long-term outcome by initial and final nadolol dose

\begin{tabular}{|c|c|c|c|c|c|}
\hline \multirow{2}{*}{$\begin{array}{l}\text { Dose } \\
\text { entering } \\
\text { Long-term }\end{array}$} & \multirow[t]{2}{*}{$n$} & & \multicolumn{3}{|c|}{ Final dosage-long-term } \\
\hline & & & $\begin{array}{l}\text { Nadolol } \\
20 \mathrm{mg} \\
\text { o.d. }\end{array}$ & $\begin{array}{l}\text { Nadolol } \\
40 \mathrm{mg} \\
\text { o.d. }\end{array}$ & $\begin{array}{l}\text { Nadolol } \\
80 \mathrm{mg} \\
\text { o.d. }\end{array}$ \\
\hline Nadolol $20 \mathrm{mg}$ & 5 & $\begin{array}{l}\text { Controlled* } \\
\text { Uncontrolled } \\
\text { D/C, ADR }\end{array}$ & $\begin{array}{l}2 \\
0 \\
0\end{array}$ & $\begin{array}{l}2 \\
1 \\
0\end{array}$ & $\begin{array}{l}0 \\
0 \\
0\end{array}$ \\
\hline Nadolol $40 \mathrm{mg}$ & 18 & $\begin{array}{l}\text { Controlled* } \\
\text { Uncontrolled } \\
\text { D/C, ADR }\end{array}$ & $\begin{array}{l}1 \\
0 \\
0\end{array}$ & $\begin{array}{r}12 \\
1 \\
4\end{array}$ & $\begin{array}{l}0 \\
0 \\
0\end{array}$ \\
\hline Nadolol $80 \mathrm{mg}$ & 10 & $\begin{array}{l}\text { Controlled* } \\
\text { Uncontrolled } \\
\text { D/C, ADR }\end{array}$ & $\begin{array}{l}0 \\
0 \\
0\end{array}$ & $\begin{array}{l}5 \\
0 \\
0\end{array}$ & $\begin{array}{l}3 \\
1 \\
1\end{array}$ \\
\hline
\end{tabular}

$\mathrm{D} / \mathrm{C}=$ Discontinued.

$\mathrm{ADR}=$ Adverse reaction.

${ }^{*} \mathrm{IOP}<22 \mathrm{mmHg}$ (both cyes).

from Fig. 1 and Table 1 (short-term) and from Fig. 2 and Table 6 (long-term). Overall, eight patients treated with nadolol. (15.7\%) were discontinued for such reactions. All but one of them were receiving either $40 \mathrm{mg}$ or $80 \mathrm{mg}$ daily. With the exceptions of one patient with bradycardia and another with palpitations the complaints were 'loss of energy', 'fatigue', and 'tiredness'. Other patients reported mild and transient reactions of a similar nature, but with continuation of therapy symptoms usually abated.

No adverse reactions were reported among the patients treated with timolol.

\section{Discussion}

This study of patients with chronic simple glaucoma demonstrates that the IOP lowering effect of orally administered nadolol $20 \mathrm{mg}$ and $40 \mathrm{mg}$ is equivalent to that of a twice daily regimen of $0.25 \%$ or $0.5 \%$ timolol eye drops. Higher doses of this $\beta$ blocker, as are commonly used in the management of systemic hypertension, are unnecessary. Nadolol's efficacy is well maintained over relatively prolonged periods of time.

Blood pressure and heart rate reductions for the three doses of nadolol used (20,40, and $80 \mathrm{mg}$ daily) corresponded closely to those obtained in the normal volunteer study.' In that study it was evident that, at the low doses of nadolol used, the ocular effect was considerably greater than the cardiovascular effects. This was not so obvious in our clinic patients, because baseline IOPs were not allowed to reach a maximum untreated level.

In most patients oral nadolol was well tolerated, and some expressed the wish to continue taking tablets rather than return to topical medication. A few patients did incur some of those side effects associated with $\beta$ blockers, but at the $20 \mathrm{mg}$ daily dosage level only one was discontinued for this reason ('slight tiredness').

Patient preference apart, we conclude that a $20 \mathrm{mg}$ or $40 \mathrm{mg}$ nadolol tablet taken once daily is sufficient to control the IOP of most patients with chronic simple glaucoma. This approach to therapy, we believe, would be preferable to topical medication in two situations; first, for reasons of practicality and cost in patients already receiving $\beta$ blockers for cardiovascular indications and second, in patients for whom the instillation of eye drops is difficult or (without help) impossible.

\section{References}

1 Williamson J, Atta HR, Kennedy PA, Muir JG. Effect of orally administered nadolol on the intraocular pressure in normal voluntecrs. Br J Ophthalmol 1985; 69: 38-40.

2 Wettrell K. Pandolfi M. Effect of oral administration of various beta-blocking agents on the intraocular pressure in healthy voluntecrs. Exp Eye Res 1975; 21: 451-6.

3 Ohrstrom A, Pandolfi M. Regulation of intraocular pressure and pupil size by $\beta$-blockers and epinephrine. Arch Ophthalmol 1980; 98: $2182-4$ 